\title{
Modelling the tsunami free oscillations in the Marquesas (French Polynesia)
}

\author{
S. Allgeyer, ${ }^{1,2, *}$ H. Hébert ${ }^{1}$ and R. Madariaga ${ }^{2}$ \\ ${ }^{1}$ CEA, DAM, DIF, F-91297 Arpajon, France.E-mail: sebastien.allgeyer@anu.edu.au \\ ${ }^{2}$ École Normale Supérieure, Laboratoire de Géologie, 24 Rue Lhomond, 75231 Paris Cedex 5, France
}

Accepted 2013 February 13. Received 2012 December 14; in original form 2011 October 14

\begin{abstract}
SUMMARY
The tsunami resonance inside basins (closed or semi-enclosed) depends on the period of the incident waves, reflection and energy dissipation, characteristics of the boundary and the geometry of the basin. When waves continuously enter the basin, they cause abnormal water level fluctuations and produced damage if their periods are close to the periods of free oscillation of the basin. These resonant oscillations inside harbours, bays, or other semi-enclosed or closed basins can have a direct influence on the management of harbours, shipping and coastal uses. So, it is important to determine these free oscillations. These resonant characteristics have been observed in the Marquesas, an archipelago prone to tsunami amplification, during the last three tsunamis (Samoa 2009, Maule 2010, Tohoku 2011). These events were recorded by the two tide gauges located in the Marquesas. In this archipelago, there are two monitored bays : the first one is located in Hiva Oa Island (Tahauku Bay) and the second in Nuku Hiva Island (Taihoae Bay). For all these tsunamis, more than $3 \mathrm{~d}$ of water tidal resonance were recorded. In this work, we make a free oscillation analysis of the Marquesas Archipelago using real tide gauge data, simulated tsunami data and theoretical computations. During the last century, this archipelago was hit by several trans-Pacific tsunamis. It is interesting to note that, following different tsunami reports the bays responded differently depending on the earthquake source region. For example, Tahauku and Atuona, two bays in Hiva Oa Island only $1 \mathrm{~km}$ apart, have different responses depending on the tsunami, as it was observed in 1946 (Aleutian earthquake) and 1960 (Chile earthquake). For this reason, we study the azimuthal dependence of the excitation of the free oscillation modes, and we show that some azimuths enhance tsunami amplification.
\end{abstract}

Key words: Time-series analysis; Numerical solutions; Fourier analysis; Wavelet transform; Tsunamis; Pacific Ocean.

\section{INTRODUCTION}

Within an interval of a little more than $2 \mathrm{yr}$, three important tsunamis propagated across the Pacific Ocean, and several warning messages were issued from the Pacific Tsunami Warning System based in Hawaii. The first one, on 2009 September 29 at 17:48 UTC, triggered by an earthquake of magnitude $M_{\mathrm{w}} 8.0$, was located $195 \mathrm{~km}$ south to the Samoa Islands $\left(15.559^{\circ} \mathrm{S}, 172.093^{\circ} \mathrm{W}\right.$ USGS location) and reached the French Polynesia, located in the middle of the Pacific Ocean, about $5 \mathrm{hr}$ after the main shock. The second one, on 2010 February 27 at 06:34 UTC, was triggered by the largest earthquake recorded in South America since the 1960s. The

\footnotetext{
* Now at: Research School of Earth Sciences, Australian National University, Canberra, ACT 0200, Australia.
}

Maule earthquake $\left(M_{\mathrm{w}} 8.8\right)$ occurred to the northwest of Concepcion Chile $\left(36.41^{\circ} \mathrm{S}, 73.24^{\circ} \mathrm{W}\right)$. The last one, on 2011 March 11 at 05:46 UTC, was initiated by the $M_{\mathrm{w}} 9.0$ Tohoku-oki earthquake offshore the Honshu Island in Japan $\left(38.322^{\circ} \mathrm{N}, 142.369^{\circ} \mathrm{E}\right)$. These three tsunamis hit French Polynesia after several hours of propagation and triggered a red watch alert from the French Polynesian tsunami warning centre (CPPT, Reymond et al. 1991). Each tsunami wave train which propagated across the Pacific Ocean, reached French Polynesia with different arrival azimuths, and they produced different relative effects in the different Polynesian islands and bays.

Among them, the Marquesas Archipelago (French Polynesia) is very sensitive to tsunamis triggered around the Pacific Ocean (Sladen et al. 2007). This is due to the absence of coral reef around these islands, and the mild slope bathymetry when tsunamis approach the shores. Several times per century, French 

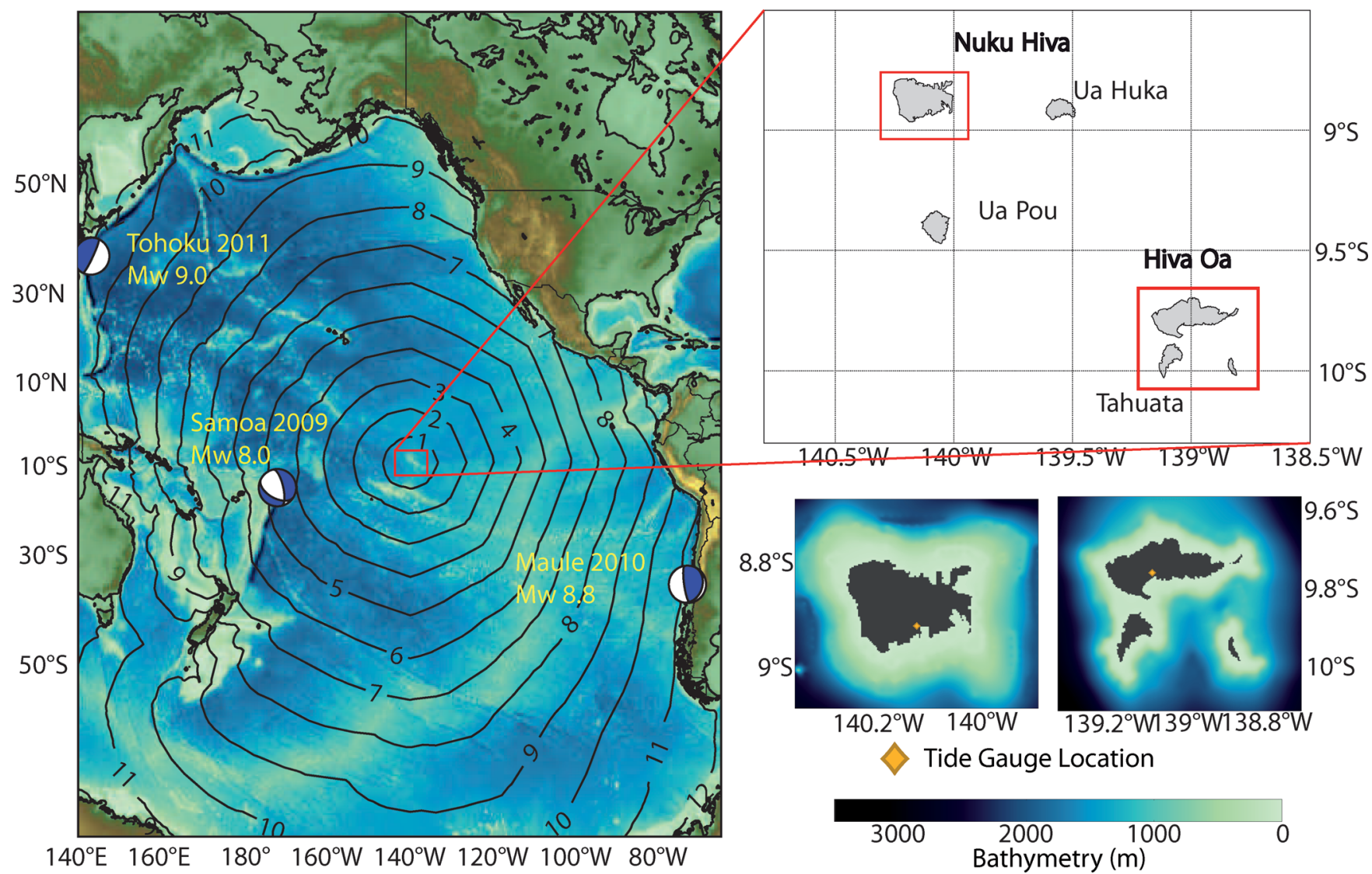

Figure 1. Localization of Marquesas Archipelago and the different islands and the three tsunami earthquakes source events. Black line represents the tsunami traveltime in hours.

Polynesia has been affected by tsunamis coming from a large variety of possible azimuths, from the Aleutians to the North (Aleutian 1946, Okal \& Hébert 2007) to South America to the southeast (Peru, Chile, Heinrich et al. 1998; Hébert et al. 2001), and also from the Tonga-Kermadec subduction zone to the southwest (Okal et al. 2004).

The tsunami amplification in bays and harbours is due to resonant effects that are excited by the arrival of long tsunami waves into a semi-enclosed water body. This occurs when the period of these waves is similar to the period of free oscillations of the water surface of the harbour (Bellotti 2007; Sahal et al. 2009). Many investigators have studied the resonance response of marine structures to long waves. At the harbour scale, Bellotti (2007) studied the response of the ancient Roman harbour of Ostia under different synthetic waves and the influence of the position of the mouth of the harbour. Horrillo et al. (2008) studied the effect of the Kuril 2006 tsunami in the Crescent City harbours using numerical simulation and observations. In the Hawaiian archipelago, Munger \& Cheung (2008) showed that inter island free oscillations modes can exist for open structures and consist in standing waves across the island chain and resonance in interconnected channels, embayments and shallow shelves. The relation between free oscillation and maximum tsunami damage was shown by Roeber et al. (2010). The knowledge of local resonance is as important for hazard mitigation as the origin and incidence direction of the tsunami. Yamazaki \& Cheung (2011) recently showed that the coupling of the shelf resonance and the fundamental oscillation mode in the Bay of Concepcion, Chile, resulted in the large unexpected wave that devastated the Talcahuano Harbour and the wave front district more than $3 \mathrm{hr}$ after the Maule
2010 earthquake. French Polynesia, located in the central Pacific Ocean is subject to various tsunami sources along the circum Pacific subduction zones, provides a good opportunity to study the influence of different tsunami azimuths.

It is well known (Bellotti 2007; Horrillo et al. 2008) that the coupling between tsunami forcing and natural modes of bays or harbours can amplify tsunami waves in a specific location through resonance. Using spectral analysis of four modelled tsunamis (Kurile 1994, Chile 1995, Mexico 1995 and Peru 1996), Hébert et al. (2001) showed that particular bays of the Marquesas Archipelago have resonant periods that are independent on the origin of the tsunami. Finally, by using these four tsunamis and two other possible source regions (Aleutian and Tonga trenches) they determined the most dangerous source zone for the Marquesas Archipelago. Nevertheless, using real source locations, a study of resonant characteristics could not be conducted in the previous study due to various changing parameters (distance to studied sites, directivity of the radiation, ... ). In the following study, we determine the periods of oscillations (eigenperiods) for selected islands of French Polynesia. To this aim, we use real tide gauge records and numerical tsunami simulation (based on non-linear shallow water theory) to make a spectral analysis based on Fourier transform (FT) and frequency time analysis of the data. An alternative way to determine free oscillations is to use analytic computations of different eigenfunctions of the wave equation to find these oscillation periods. Due to the central position of French Polynesia in the most tsunamigenic ocean, these islands are strongly exposed to far-field tsunamis. Thus, it is important to identify which source azimuths may be more dangerous for which bays. For this reason, we use a set of synthetic 


\section{(a) Tohoku}

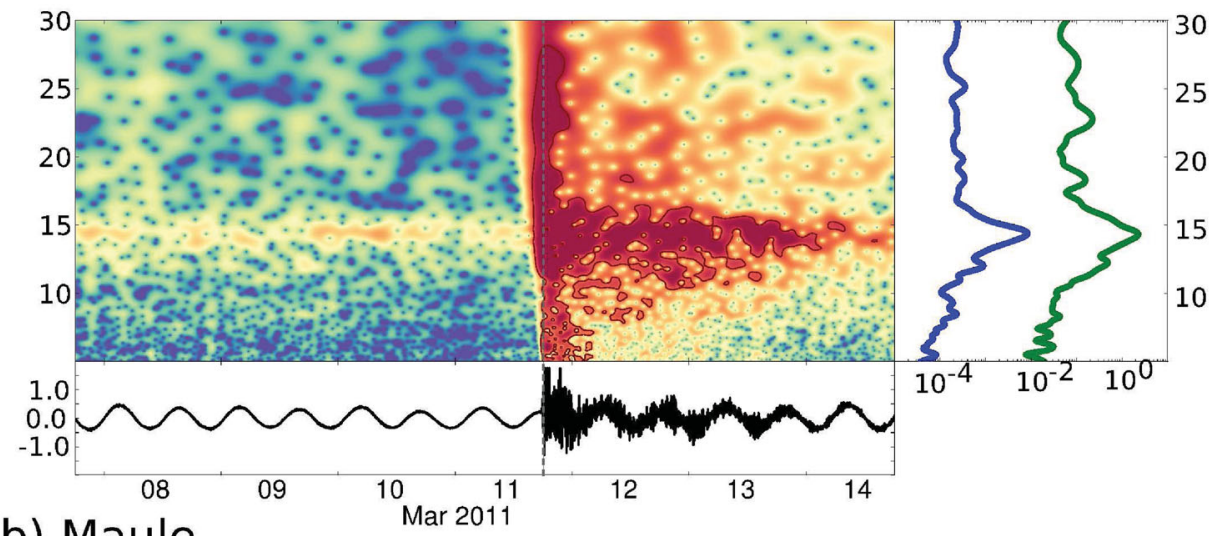

(b) Maule

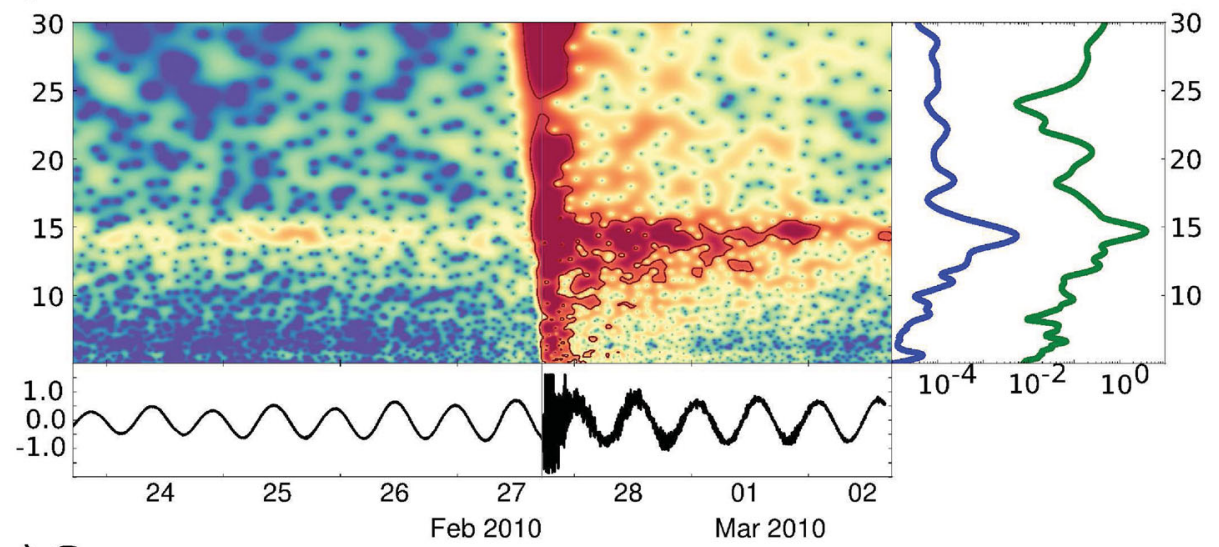

\section{(c) Samoa}

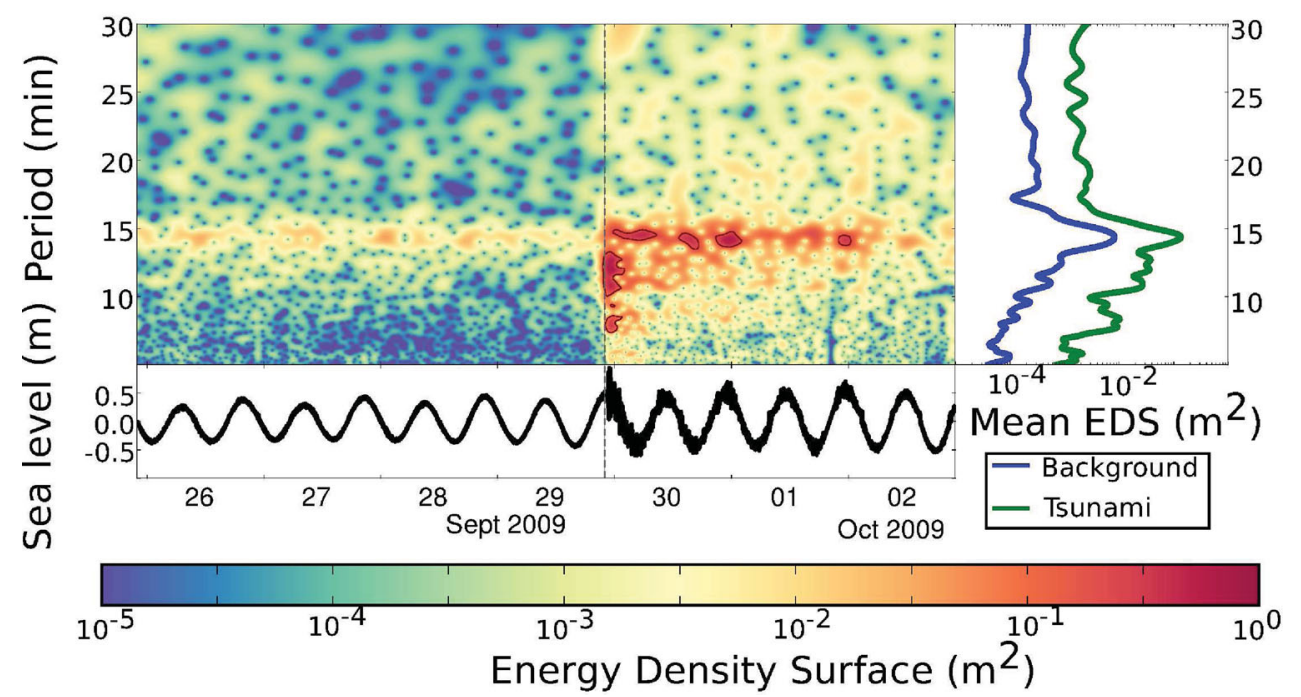

Figure 2. Wavelet analysis for the Nuku Hiva tidal gauge data for the three events: (a) Tohoku 2011, (b) Maule 2010, (c) Samoa 2009. Showing the raw tide gauge data (bottom panel), the wavelet analysis (central panel) and the mean spectra of the tsunami and the background noise. The grey dashed line symbolized the first wave arrivals.

equidistant sources, with identical parameters, to study azimuthal dependency of the excitation of these eigenperiods. With these results, we identified the source regions for which tsunami effects are the most serious and those for which the effects are the mildest. The warning system in place in Tahiti since the 1960s (Reymond et al. 1991) should benefit from such detailed study.

\section{OBSERVATIONS AND DATA ANALYSIS}

French Polynesia, located in the centre of the Pacific Ocean, is exposed to large transoceanic tsunamis triggered by earthquakes in the circum-Pacific subduction zones, the most tsunamigenic in the world. Some of these tsunamis may reach the Polynesian islands 


\section{(a) Tohoku}

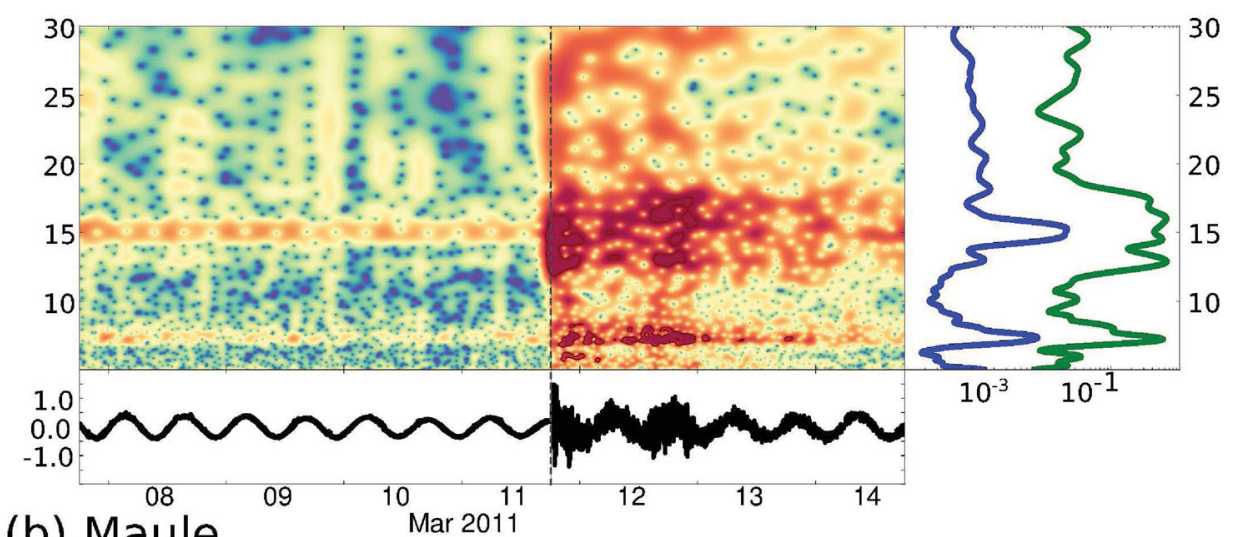

(b) Maule

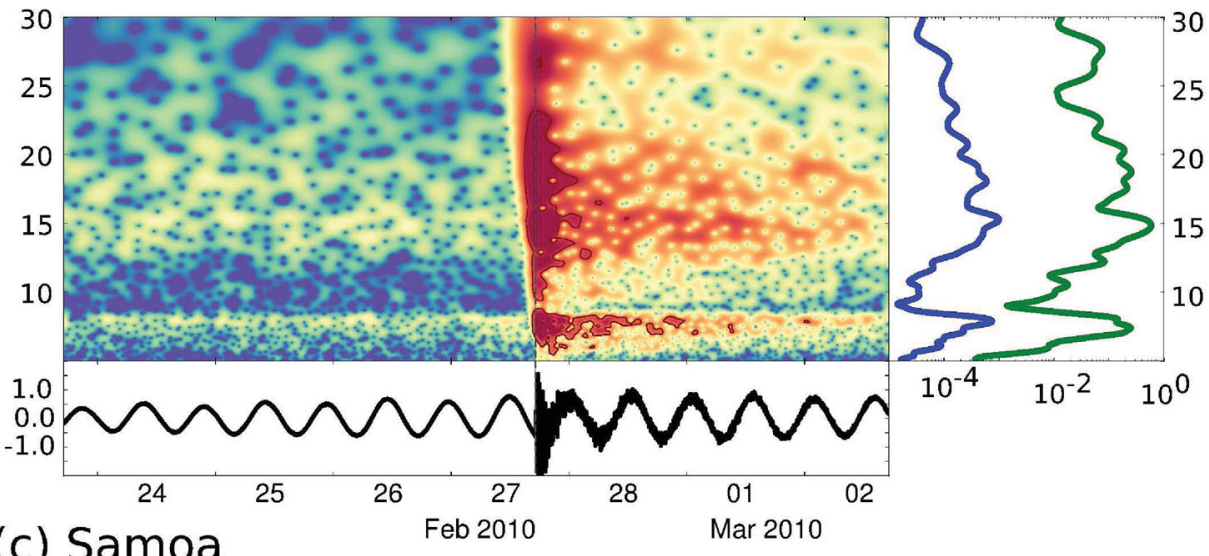

\section{(c) Samoa}
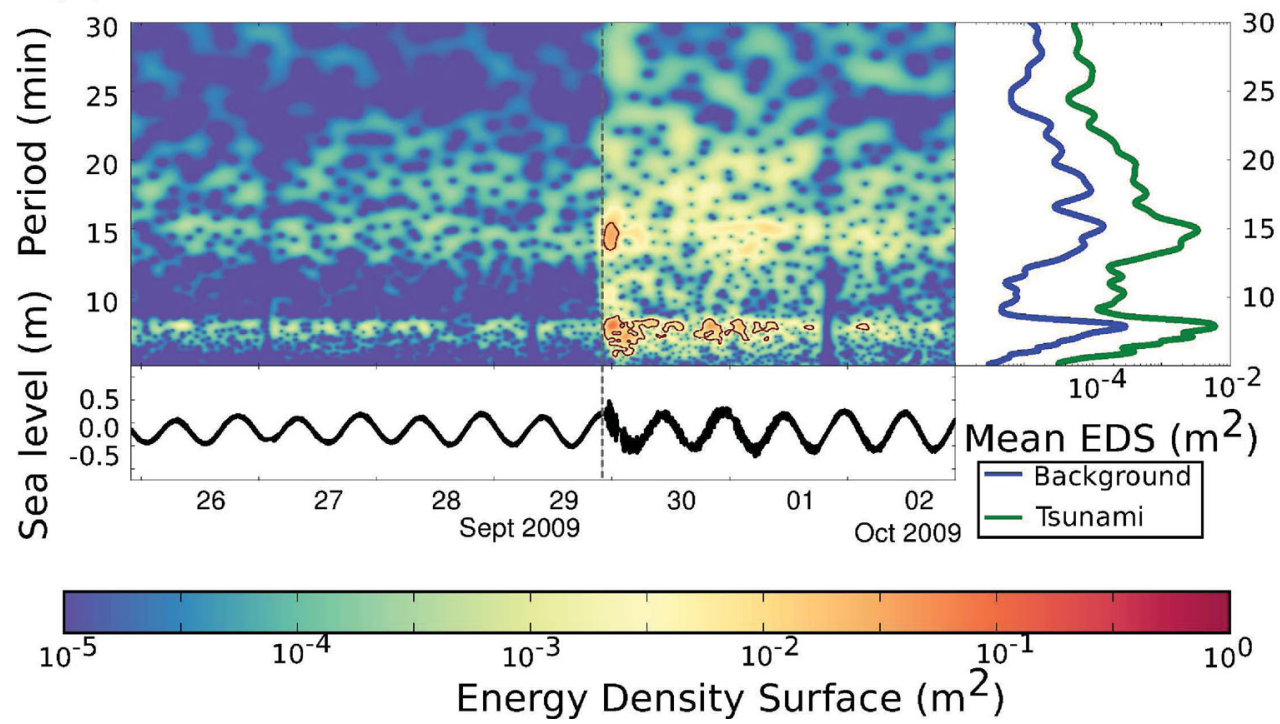

Figure 3. Wavelet analysis for the Hiva Oa tidal gauge data for the three events: (a) Tohoku 2011, (b) Maule 2010 and (c) Samoa 2009. See legend of Fig. 2 for more details.

in less than $5 \mathrm{hr}$ (as is the case for the Samoa event), while others arrive at the remote islands in 10-12 $\mathrm{hr}$ (Chilean and Japanese events; Fig. 1). As said before, the Marquesas Archipelago is the most prone to tsunami amplification; we focus our study on the Nuka Hiva and Hiva Oa islands where tide gauges have been operating in two bays for many years (Taiohae in Nuku Hiva and Tahauku in Hiva Oa).

\subsection{Methodology}

Tsunami waves are known to produce time-series with complex frequency contents that varies in time and space (Rabinovich et al. 2006; Rabinovich \& Thomson 2007). There are several possible ways to study the frequency contents of time-series. The FT is the most frequently used: it consists in decomposing signals into infinite 
Table 1. First resonant period of a circular shaped basin of $1900 \mathrm{~m}$ radius and $100 \mathrm{~m}$ depth computed after eq. (15) using $n$th zero of the derivative of the Bessel function of order $s$.

\begin{tabular}{cccccccccc}
\hline $\mathrm{s}$ & & 0 & \multicolumn{1}{c}{1} & & & 2 & \\
\hline$n$ & 0 & 1 & 2 & 0 & 1 & 2 & 0 & 1 & 2 \\
$T_{s, n}$ & 99.5 & 54.3 & 37.4 & 207.0 & 71.5 & 44.6 & 124.8 & 56.8 & 38.2 \\
\hline
\end{tabular}

(a)

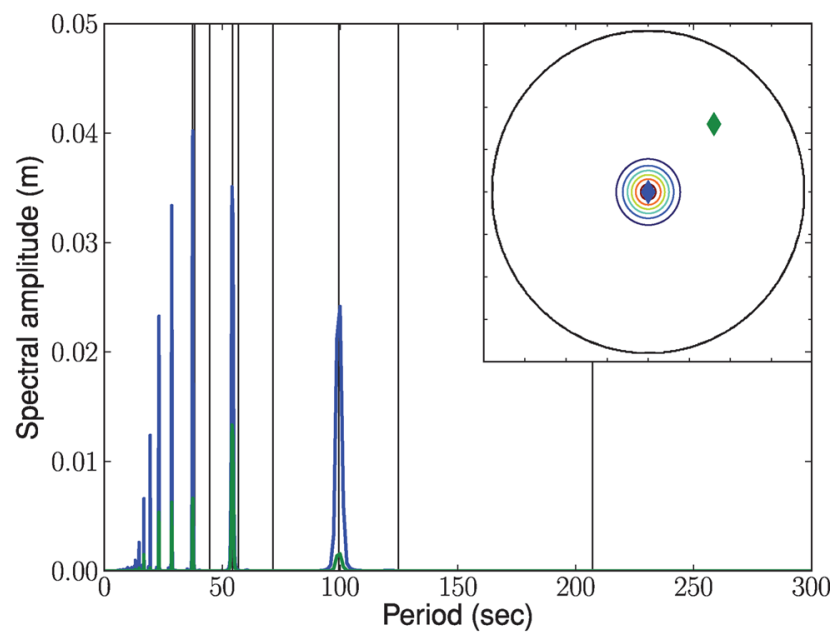

(b)

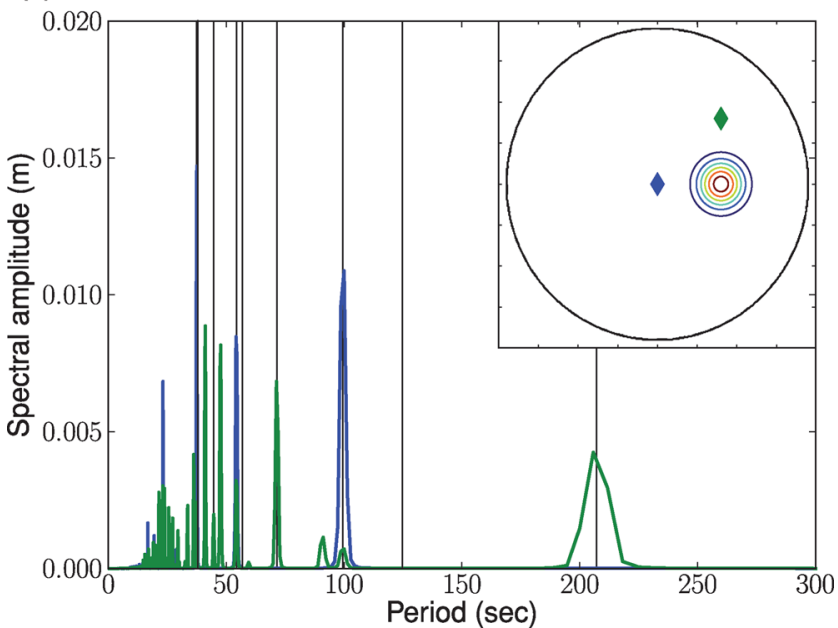

Figure 4. Determination of the resonant periods of a circular shaped basin in two different cases: (a) the source is located at the centre, and (b) offcentred. The blue and green curves show the spectral coefficients of a virtual tide gauge time-series in two different locations (at the centre of the basin for the blue one, and an off-centred one for the green). The observed picks fit well the theoretical values (black line).

sinusoids of different frequency. For our study, the main drawback of FT is the loss of the time information (Cohen 1989). To recover time information in FT, a possible solution is to divide the signal into multiple segments. This is the windowed Fourier transform (WFT) or serial Fourier transform (SFT). This method can be applied, but the selection of segments reduces the frequency resolution. Wide windows give good frequency resolution but poor time resolution, whereas narrow windows give poor frequency resolution but good time resolution. The wavelet transform (WT) solves this problem of resolution in the time-frequency domain.
In general, the WT of the time-series, $s(t)$, is defined as the inner product

$W T(\tau, b)=\left\langle\psi_{\tau, b} \mid s\right\rangle=\int_{-\infty}^{\infty} s(t) \psi_{\tau, b}^{*}(t) \mathrm{d} t$,

where $\psi_{\tau, b}^{*}(t)$ is generated from a wavelet $\Psi_{0}$ by the operation

$\psi_{\tau, b}(t)=\frac{1}{\sqrt{b}} \Psi_{0}\left(\frac{t-\tau}{b}\right)$

with $\tau$ the translation parameter and $b$ the scaling factor (Torrence \& Compo 1998). For this study, we choose to analyse our time-series with the Morlet wavelet

$\Psi_{0}(\rho)=\pi^{-1 / 4} \exp \left(\mathrm{i} \omega_{0} \rho\right) \exp \left(-\rho^{2} / 2\right)$,

where $\omega_{0}$ is the non-dimensional central frequency of the wavelet. Wavelet spectral analysis using Morlet wavelet has been previously used to study tsunami waves recorded by deep ocean buoys and coastal water level stations (Rabinovich et al. 2006; Rabinovich \& Thomson 2007). We chose not to show the classical WT (amplitude of the wavelet as a function of scaling factor $b$ and time $t$ ), but we rather display the wavelet energy density surface (EDS)

$\operatorname{EDS}(T, t)=|W T(\tau, b)|^{2}$

as a function of the Fourier period $(T)$ and time $t$. This allows us to better compare the observed data and the different synthetic simulations described in Section 3. To improve the display of the excitation mode on the wavelet EDS, the 95 per cent confidence level is highlighted. To estimate this confidence level, the hypothesis of a red noise is made (Allen \& Greenslade 2009). The red noise model that is used is the univariate lag-1 autoregressive (AR-1 or Markov) process

$x_{n}=\alpha * x_{n-1}+z_{n}$,

where $\alpha$ is assumed lag- 1 autocorrelation. We assume that the red noise follows a $\chi^{2}$ law with two degrees of freedom.

\subsection{Tidal gauge data analysis}

A spectral analysis of the Nuku Hiva tidal gauge data for the three tsunami events that we studied is shown in Fig. 2. For the three events, the analysis consists in taking a series of $7 \mathrm{~d}$ of records, centred on the first tsunami arrival identified with the dashed grey line in Fig. 2. Data are extracted from the IOC-sea level monitoring program with a sampling interval of $1 \mathrm{~min}$. The wavelet analysis of these data sets uses a Morlet wavelet with a central frequency of $\omega_{0}=6$ in eq. (3). The energy density spectrum is displayed as a function of time and period. Finally, on the left of each plot we show the mean wavelet energy density spectrum in two separate 3-D time windows. The tsunami mean spectra (in green) computed inside a window starting with the arrival of the first tsunami wave (red vertical line) and, in blue, the local background noise starting on $4 \mathrm{~d}$ before the event to avoid the leakage of the wavelet energy due to the acausal nature of the wavelet analysis. We observe from the raw data (with tide), that the tsunami waves from Tohoku 2011 (Fig. 2, top panel) and Samoa 2009 (Fig. 2, bottom panel) events arrived during high tide (i.e. when the water level rises its highest level), whereas the Maule 2010 tsunami (Fig. 2, central panel) waves arrived during low tide (i.e. when the water level stops falling). The Maule and Tohoku events produced a saturation of the sensors at $1.5 \mathrm{~m}$. This saturation produced an underestimation of the local wavelet coefficients that are not important for our study because we 

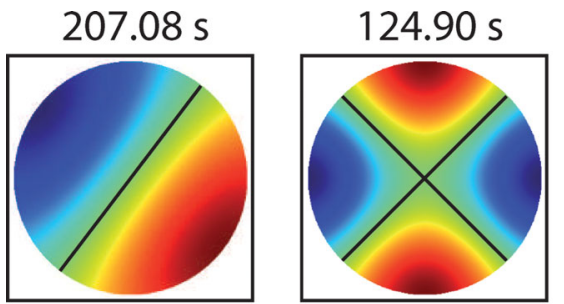

$99.45 \mathrm{~s}$

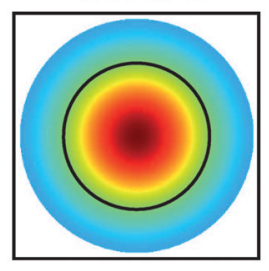

$90.84 \mathrm{~s}$

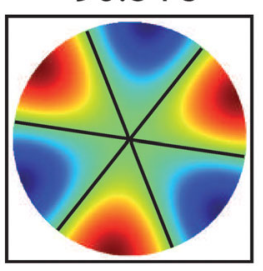

$71.48 \mathrm{~s}$
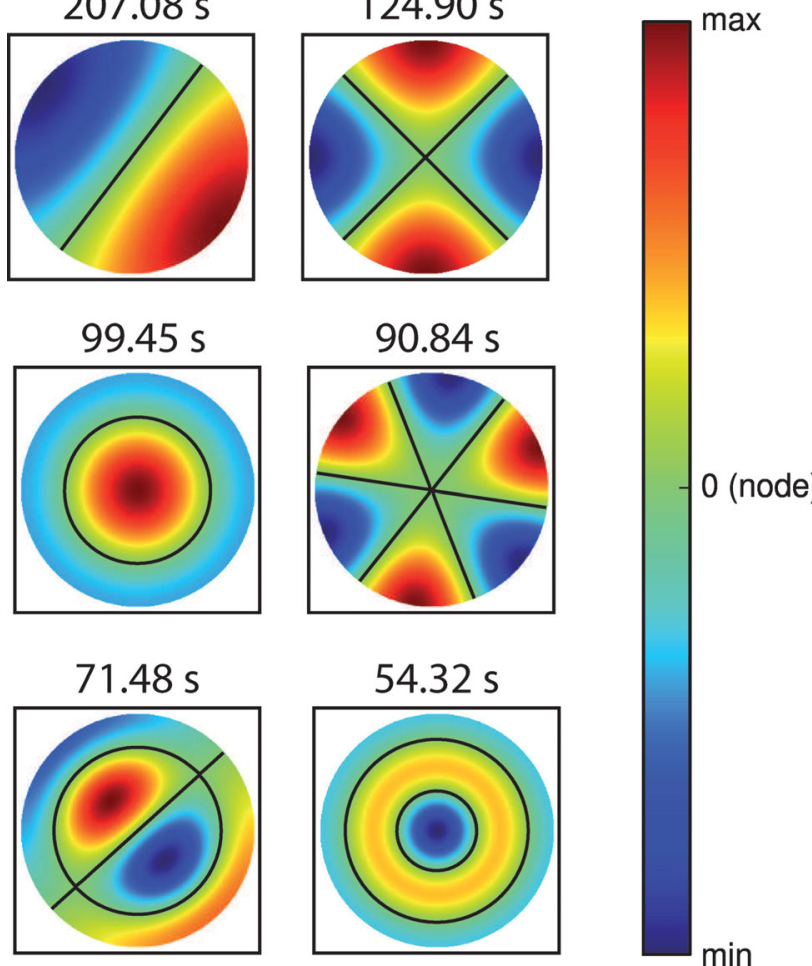

Figure 5. Determination of the resonant periods of a circular shaped basin of $1900 \mathrm{~km}$ radius and $100 \mathrm{~m}$ depth with the eigenfunction method. Only six modes are shown. Black lines represent nodes of the free oscillations.

Table 2. First resonant period of a rectangular shaped basin of $7 \mathrm{~km} \times 4 \mathrm{~km}$ and $100 \mathrm{~m}$ depth computed after eq. (16).

\begin{tabular}{cccccc}
\hline$n / m$ & 0 & 1 & 2 & 3 & 4 \\
\hline 0 & & 255.42 & 127.71 & 85.14 & 63.85 \\
1 & 446.98 & 221.77 & 122.80 & 83.64 & 63.21 \\
2 & 223.49 & 168.19 & 110.88 & 79.56 & 61.40 \\
3 & 149.00 & 128.70 & 96.96 & 73.92 & 58.69 \\
4 & 111.75 & 102.38 & 84.09 & 67.72 & 55.44 \\
\hline
\end{tabular}

make an average of the coefficients before and after the event. For the three events, a spectral maximum is observed around $15 \mathrm{~min}$. This oscillation period is identified in the background signal. For the Samoa event, we can note that there is only an amplification factor of 10 between the mean energy density spectra before and after the event whereas a factor 100 is observed for the two other events.

The same spectral analysis is applied to the Hiva Oa tide gauge data and shown in Fig. 3. For this island, there was no saturation of the sensor. The mean wavelet energy looks larger in frequency contents than the Nuku Hiva data. Three resonant periods can be identified. The largest with resonant periods from 17 to $21 \mathrm{~min}$ is well defined for the Maule tsunami data (Fig. 3, central panel). The second, with periods between 13 and $16 \mathrm{~min}$, is observed for the three events, with different shapes going from a single peak for the Samoa event (Fig. 3, bottom panel), to wide peaks observed for the Tohoku event (Fig. 3, top panel). The last period range, present in all data, varies from 5 to $8 \mathrm{~min}$ of period. Similarly, to the Nuku Hiva tidal gauge data analysis, we note that there is only an increase by a factor 10 of the mean EDS before and after the Samoa first arrival and a factor 100 for the Maule event. Nevertheless, only a factor around 10 is observed for the Tohoku data; this shows that Nuku Hiva is less affected by waves coming from the northwest.

A comparison between the two bays (Figs 2 and 3 ) shows that the level of mean spectral energy differs with respect to the background noise, from one event to another with an approximate mean energy of $10^{-5} \mathrm{~m}^{2}$ for the Samoa tsunami and $10^{-3} \mathrm{~m}^{2}$ for the Maule and Tohoku data. This difference is due to the tidal peak to peak amplitude which is of $0.2 \mathrm{~m}$ for the Samoa event in 2009 September and of $1.0 \mathrm{~m}$ for the other events in 2010 February and 2011 March.

\section{TSUNAMI FREE OSCILLATION DETERMINATION}

\subsection{Spectral analysis method}

This method uses a similar technique of time-series analyses as in the previous section except that we apply it to virtual tide gauges based on the tsunami simulations rather of real data. The numerical simulation is based on the hydrodynamic equation under the non-linear shallow water approximation. In the most general case, these equations are divided into a set of two hyperbolic equations, containing an equation of motion

$$
\frac{\partial \vec{u}}{\partial t}+(\vec{u} \cdot \vec{\nabla}) \vec{u}+\vec{f} \times \vec{u}=-\vec{g} \nabla \eta
$$

and an equation of continuity

$$
\frac{\partial(\eta+h)}{\partial t}+\nabla \cdot(\vec{u}(\eta+h))=0 .
$$

In these equations, $\vec{u}$ denotes the velocity vector, $\eta$ is the sea level variation around the mean sea level $h, f$ is the Coriolis parameter and $g$ represents the acceleration of gravity. This set of equations is solved with a finite difference Crank \& Nicolson (1947) scheme applied to a series of nested bathymetric grids to account for the shoaling effect that occurs close to the shores. This model has been tested and validated in numerous cases (see, e.g. Hébert et al. 2001; Sahal et al. 2009; Allgeyer et al. 2012). In these simulations, the source term is chosen as a generic 2-D Gaussian function.

\subsection{Eigenfunction decomposition}

To compute the free oscillation surface eigenfunction, we start searching possible resonance amplifications by using the shallow water equations (eqs 6 and 7) in the linearized form without external forces and leads to the hyperbolic wave equation

$\frac{\partial^{2} \eta}{\partial t^{2}}-g \nabla(h \nabla \eta)=0$.

Normal modes of a given water body can be calculated as an eigenvalue problem (Mei et al. 2005). In the normal mode theory, the independence of time and space components in the sea level variation is assumed,

$\eta(x, y, t)=\eta(x, y) \times \exp (\mathrm{i} \omega t)$

leading to an eigenmode equation for the sea level height $\eta$

$g \vec{\nabla}(h \nabla \eta)+\omega^{2} \eta=0$.

The Helmholtz equation (eq. 10) is solved on the bathymetric grid using the following boundary conditions. The Neumann boundary condition,

$\frac{\partial \eta}{\partial \vec{n}}=0$ 
is applied along the coast line and the Dirichlet boundary condition,

$\eta=0$,

is used along the open water boundary. The Dirichlet boundary condition imposes a node of oscillation on the boundary of the domain; this is only satisfied if the dimension of the computational domain is large enough so that the free oscillation surface does not reach the boundary or the water depth is large enough so that the water level elevation can be neglected.

\subsection{Comparison between both methods}

To test our methods, we use a simple case following Yalciner \& Pelinovsky (2007). It consists in finding the resonant frequency of a circular shaped basin of radius $a=1900 \mathrm{~m}$ and a constant depth $d=100 \mathrm{~m}$. Solving the Helmholtz equation with cylindrical coordinates, we obtain that the elevation is given by the expression

$\eta(r ; \theta ; t)=J_{s}(k r)\left(A_{s} \cos (s \theta)+B_{s} \sin (s \theta)\right) \cos (\omega t)$

as a function of $r$ the radial distance, where $\theta$ is the angular coordinate, $A_{s}$ and $B_{s}$ are empirical constants and $s$ denotes the order of the Bessel function $J_{s}$. Applying the Neumann boundary condition in eq. (13), we obtain the period equation

$\left.J_{s}^{\prime}(k r)\right|_{r=a}=J_{s}^{\prime}(k a)=0$.

So, the resonant period is given by

$T_{s, n}=\frac{2 \pi a}{j_{s, n} \sqrt{g h}}$

with $g$ the gravity acceleration and $j_{s, n}$ the $n$th zero of the derivative of the Bessel function of the first kind and of order $s$. Table 1 shows these first computed theoretical periods.

The resonant periods were computed with both methods. Fig. 4 shows the results of the spectral analysis method (described in Section 3.1). Two numerical simulations were done with an initial gaussian-shape deformation characterized by a maximal amplitude of $1 \mathrm{~m}$ located at the centre of the basin (Fig. 4a) and another one off-centred (Fig. 4b). For these two simulations, the amplitude spectra are represented at two locations: at the centre (in blue) and off-centre (in green). The black lines represent the first nine theoretical periods computed with eq. (15) (with the indices $s$ and $n$ varying from 0 to 2 as shown in Table 1). The analysis of this figure shows that, when the source is at the centre only a few of the modes are excited; while when the source is of-centre more free oscillation modes are resolved.

Fig. 5 represents six of the different eigenfunctions calculated using the method described in Section 3.2. This computation was done using the PETSc and SLEPc MPI-libraries (Hernandez et al. 2005; Balay et al. 2008). It can be noted that both methods produce similar estimates of the eigenperiods.

Main differences come from the method which is used. In the first case, we use a dynamic method. This implies that there is a strong dependency between the result, the source used and the observation point. The centred source can only excite the radial free oscillation modes. An off-centred source can better resolve all the modes, but the effect of the observation point is important: if the observation point is located at a node of oscillation, this period cannot be determined (see, e.g. the $204 \mathrm{~s}$ mode absent on Fig. $4 \mathrm{~b}$ for the blue point).

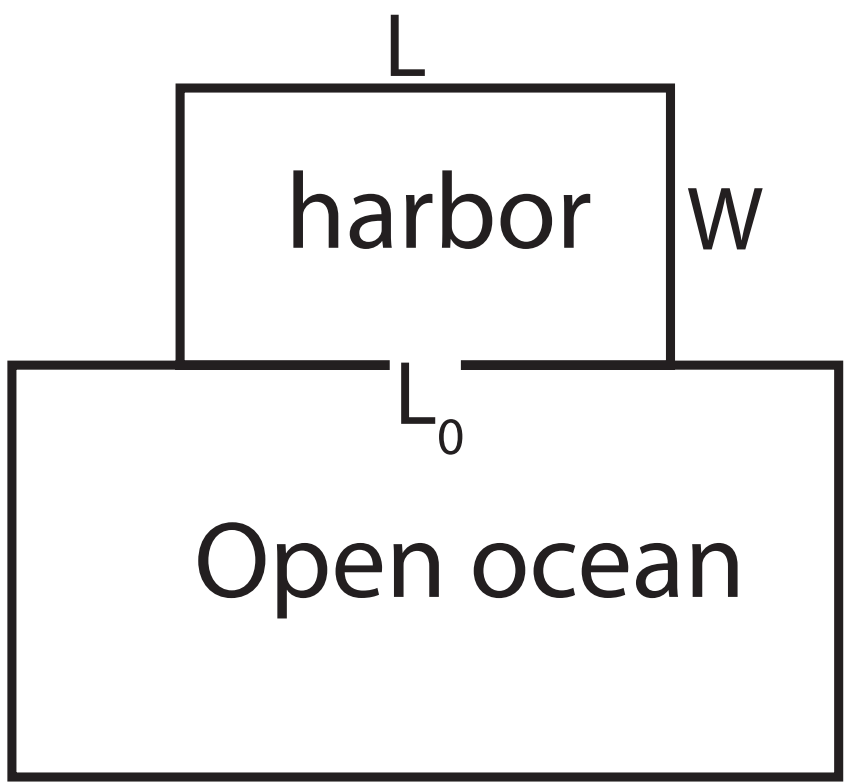

Figure 6. Configuration used for the simulation: a closed rectangular shape basin $(7 \mathrm{~km} \times 4 \mathrm{~km})$ is connected to the open ocean $(21 \mathrm{~km} \times 12 \mathrm{~km})$ by a mouth of length $l_{0}$.

\subsection{Free oscillations of open bays}

Up to now, we have studied closed bays. In the Marquesas, we are dealing with open bays; in this section, we will study the difference between closed and open bays on the free oscillation modes.

To study the effect of an open boundary, we consider a basin with a rectangular shape of length $L=7 \mathrm{~km}$ and width $W=4 \mathrm{~km}$ with a constant depth of $100 \mathrm{~m}$. The resonant frequencies of such a rectangular basin are well known (Rabinovich 2009).

$T_{n, m}=\frac{2}{\sqrt{g h}}\left(\frac{n^{2}}{L^{2}}+\frac{m^{2}}{W^{2}}\right)^{-1 / 2}$,

where $n$ and $m$ represent the number of nodes along length and width, respectively. Table 2 shows the first computed theoretical periods.

Fig. 6 shows the methodology that we use to study the effect of an open boundary. We insert an open segment on the previous rectangular shape at the middle of the length with a mouth of length $L_{0}$ towards an open basins (where the length and width are three times those of the closed basin) and with the same depth.

Fig. 7 shows the spectral response of this geometry for different values of the $L_{0}$ from the fully closed basin (a), to a fully open basin (c). Red lines symbolize the value obtained using eq. (16). For the closed case (a), we have a good fit between the observed and theoretical values. By opening this geometry (case b), we observe that the peaks are wider and that the free oscillation periods are shifted towards lower values. We also observe that a new longperiod peak appears at approximatively $1000 \mathrm{~s}$. This new mode is characterized by a large bandwidth. For the full open configuration (case c), only a few theoretical values are observed.

Fig. 8 shows the results obtained using the eigenfunction method. Only the two or three first modes are displayed and the open ocean basin has been cut to better see the inner basin. For the closed basin case (a), we obtain results which are in good agreement with the theory. By opening the basin, these modes are slightly perturbed with the modification of the full-reflective condition of the south boundary, allowing an outflow of wave energy. The new mode (mode 0 , also called Helmholtz mode or pumping mode) is characterized 

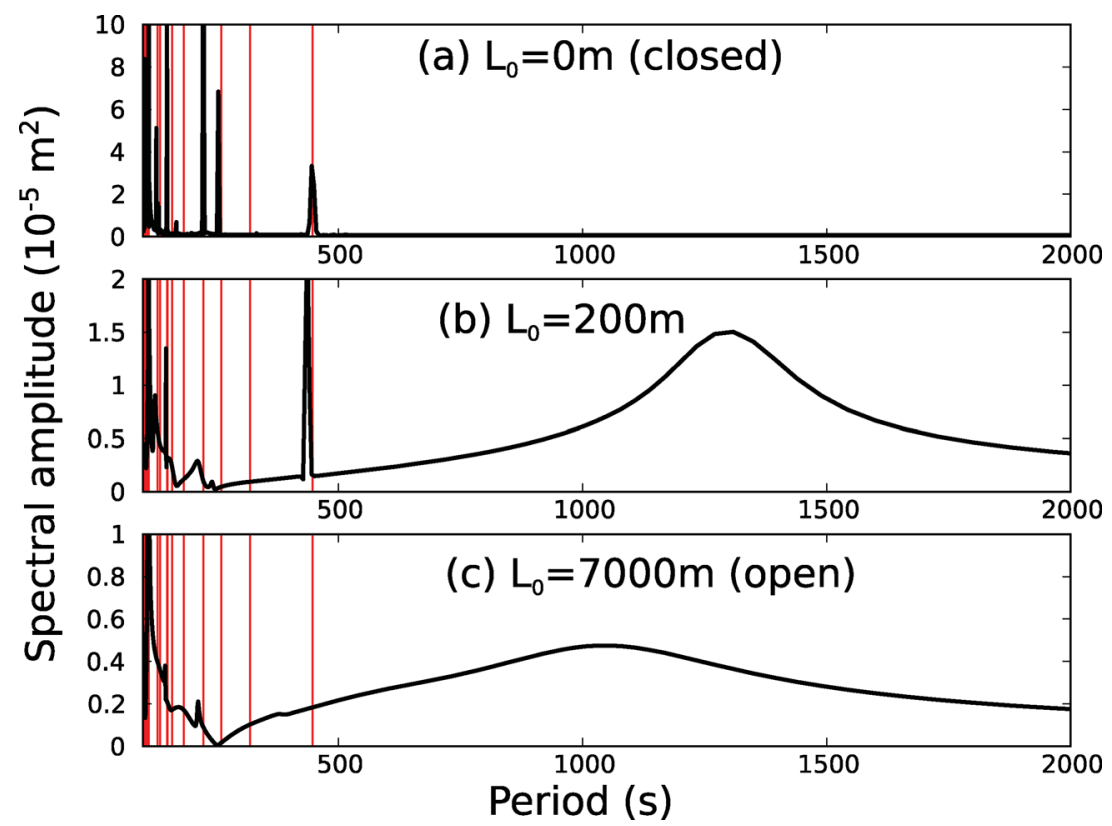

Figure 7. Determination of the resonant periods of a rectangular shape basin with different mouth dimension: (a) no mouth, (b) mouth of $200 \mathrm{~m}$, (c) mouth of $7000 \mathrm{~m}$ (i.e. full open). Red lines symbolized the theoretical value for a closed basins (eq. 16) and Table 2.

\section{Closed}

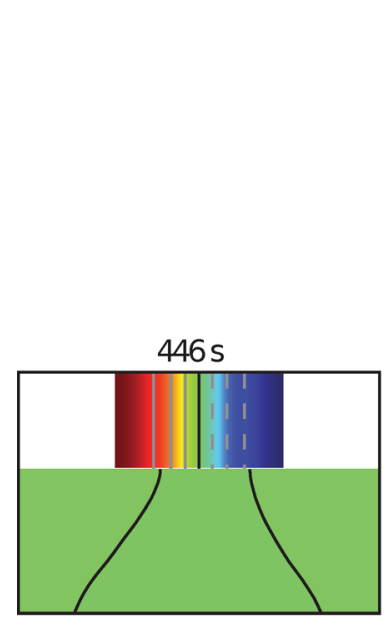

2545

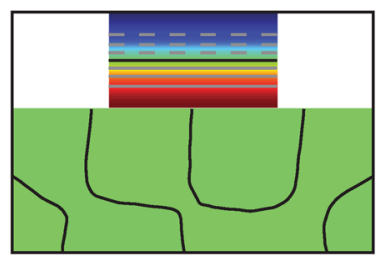

Intermedate

$1414 \mathrm{~s}$

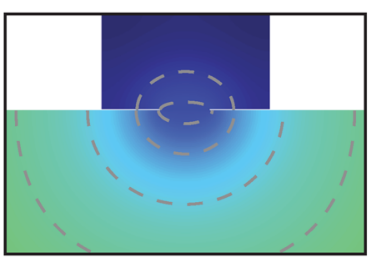

$435 \mathrm{~s}$

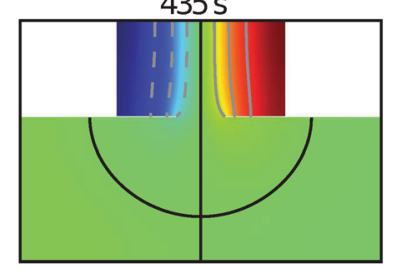

$251 s$

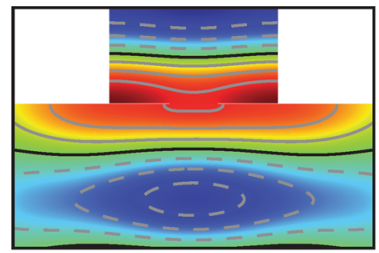

Open

$1215 \mathrm{~s}$

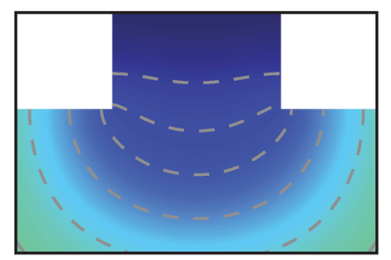

Mode 0

$388 \mathrm{~s}$

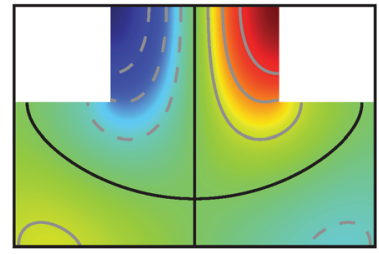

Mode I

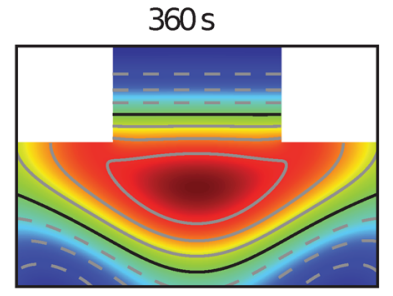

Mode II

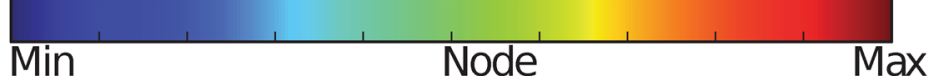

Figure 8. Determination of the resonant periods of an open rectangular shape basin using the eigenfunction methods, for the same configuration of Fig. 7. The open ocean basin has been cut to better represent the inner basin. Only the two (three) first modes are represented. 
by uniform oscillation of the inner basin. This mode cannot be observed in the closed basin due to the mass conservation principle. Due to the wider bandpass of the resonant peak, small differences could appear in the value obtained by the both methods.

The main effect of the opening of the basin is the leak of energy towards this open basin adding attenuation to the resonant oscillation which make it more complicated to identify. In the following, we will call this kind of oscillation 'semi-free oscillation' or 'semiresonant period'.

\section{RESONANCE MODES AND THEIR AZIMUTHAL AND DISTANCE DEPENDENCE}

\subsection{Computational initial conditions}

Methods presented in Section 3.2 need to have a bathymetric grid to allow the computation. For the spectral analysis, we use a fivelevel multigrid numerical simulation over the Pacific Ocean with resolution from $4^{\prime}$ over the open ocean (domain shown in Fig. 1) to $5 \mathrm{~m}$ for the smallest grid (Fig. 9). All grids are extracted for the GEBCO 30" data set and previous studies (Hébert et al. 2001; Sladen et al. 2007). For the eigenfunction decomposition, we only need to use the last grid level.

\subsection{Identification of the period of the semi-resonant period}

Fig. 9(a) shows the different free oscillation modes for the Marquesas Archipelago as a cumulative power spectral energy for each computational node for the Maule earthquake (seismic source proposed by Delouis et al. 2010). Similar results were obtained using the tsunami due to the Samoa and Tohoku earthquakes. Despite the low resolution of our computational grids (space interval of $2 \mathrm{~km}$ ), some spectral maximum values are located around Nuku Hiva and Hiva Oa islands (see Fig. 1 for island location). For Hiva Oa (Southern Island), a resonance interaction is clearly located between Hiva $\mathrm{Oa}$ and Tahuata islands.

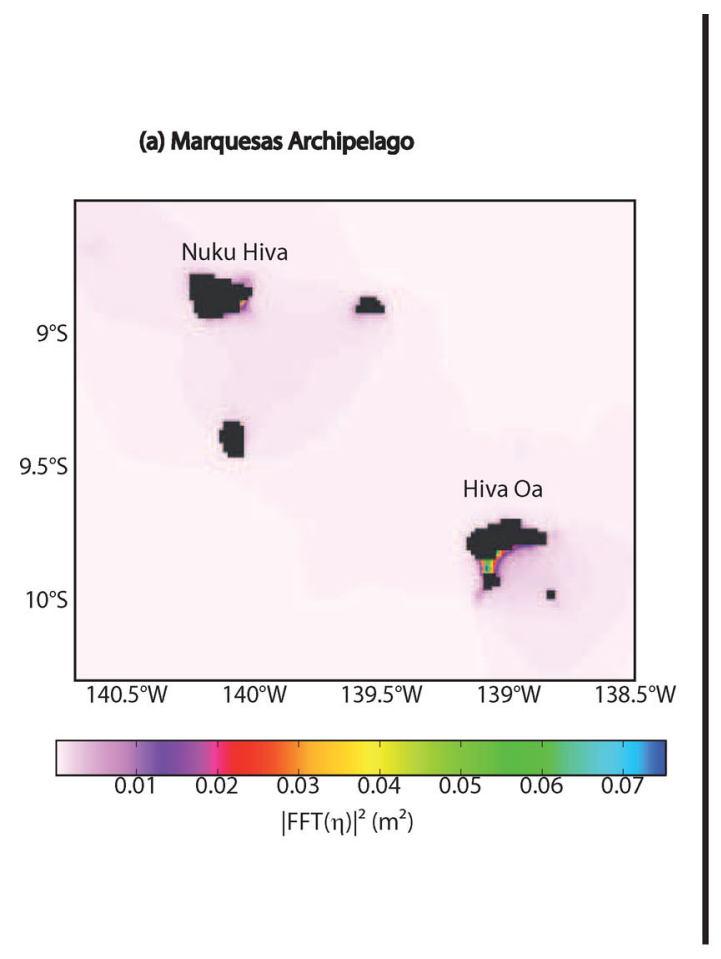

(d) Nuku Hiva

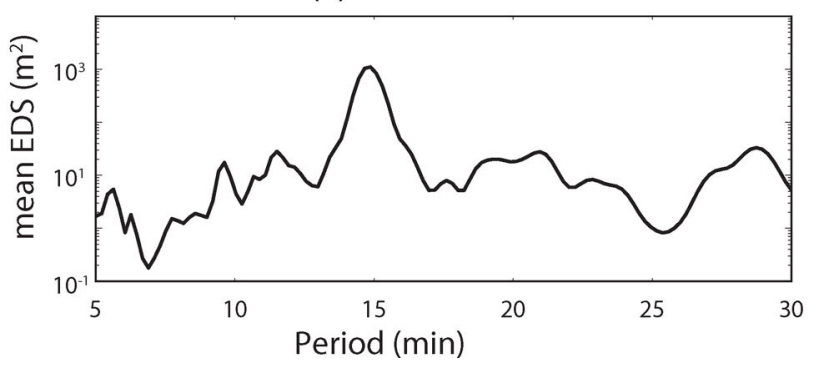

(b) Nuku Hiva
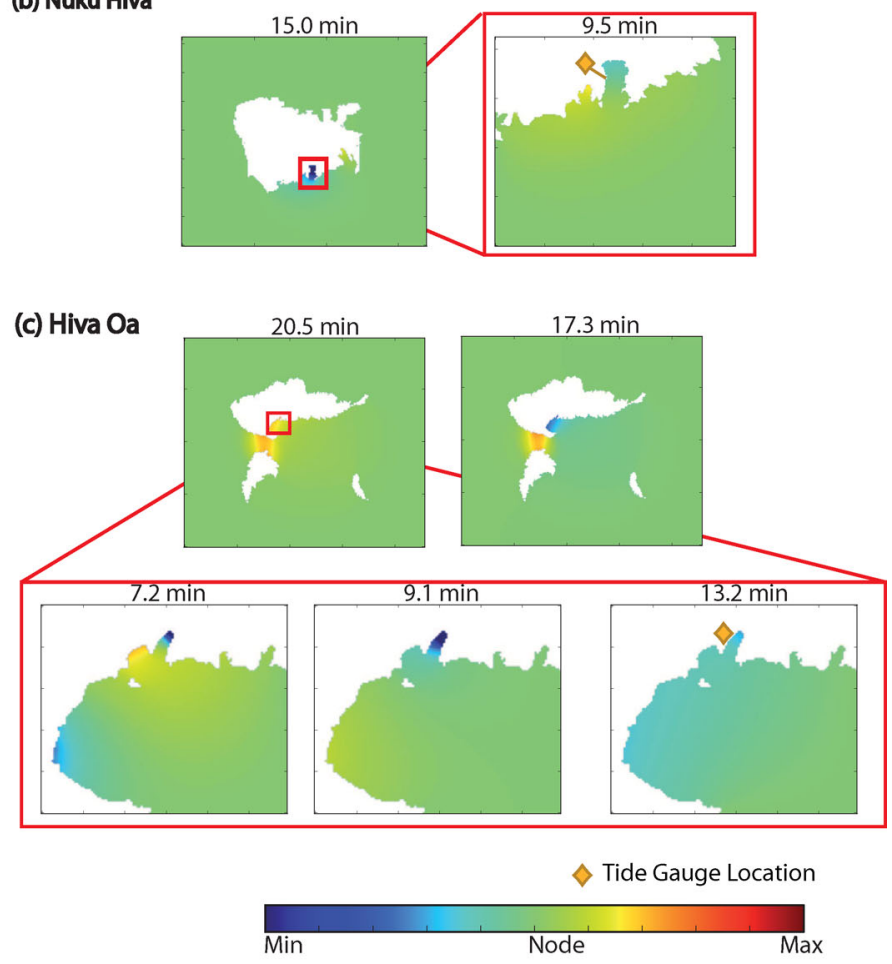

(e) Hiva Oa

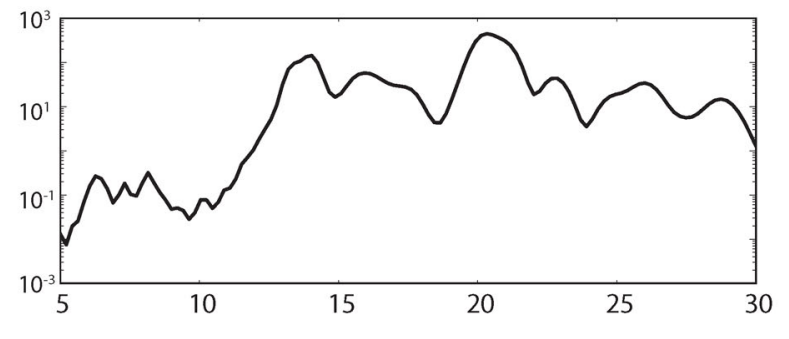

Figure 9. Different free oscillation modes for the Marquesas Archipelago with (a) a view of all the archipelago using spectral analysis of a numerical simulation of the Maule event, ( $b$ and c) eigenfunction decomposition of the two main islands: Nuku Hiva (b) and Hiva Oa (a). Orange diamonds denote the location of the tidal gauges, (d) and (e) show synthetic spectra computed with arbitrary source for Nuku Hiva and Hiva Oa. 


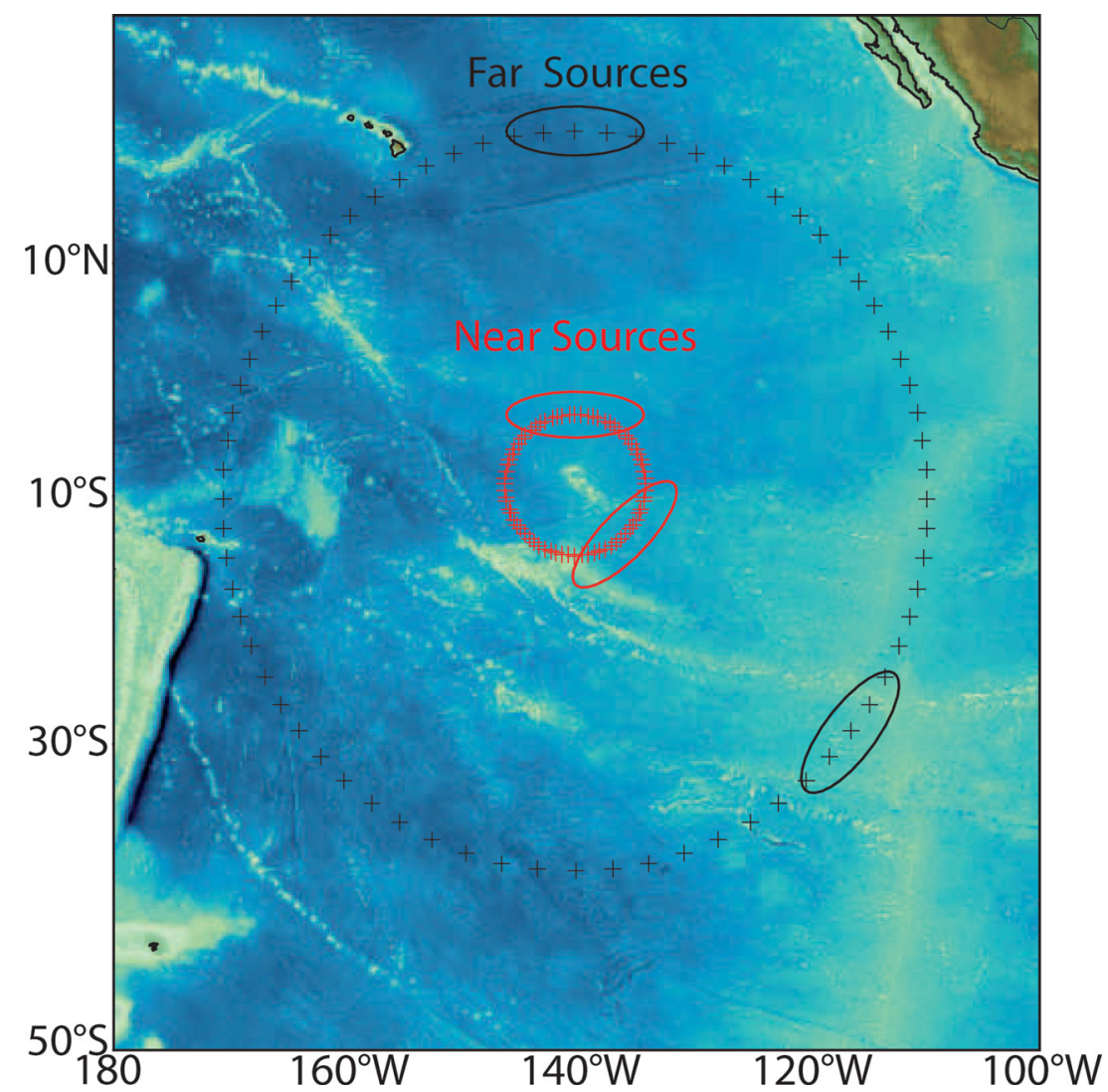

Figure 10. Location of the different sources used for the study of azimuthal dependence of the excitation of free oscillations in Nuku Hiva and Hiva Oa islands in two cases: far (in black) and near sources (in red). All centre of sources are represented.

Figs 9(b) and (c) show the result of the eigenfunction investigation. The other way to compute free oscillations is represented in Figs 9(d) and (e). The results of both methods are similar with a main semi-free oscillation of 15 min for Nuku Hiva Island which can be explained by the main oscillation of the bay containing the tidal gauge (Figs 9b and d). Concerning Hiva Oa, the eigenvalue methods show weak free oscillation periods of $20.5,17,13,9$ and $7 \mathrm{~min}$. These results are similar to those obtain from real tide gauge analyses on Fig. 3. Only the main free oscillation modes related to the tide gauge data analysis are shown. The main oscillation of $20.5 \mathrm{~min}$ is not strong on the real tide gauge analyses (with a spectral range of 17-21 min). This implies that it is a highly dissipative free oscillation. This is confirmed in Fig. 9(b) where the 20.5-min mode is an interaction between the islands of Hiva Oa and Tahuata. The other modes (7, 9 and $13 \mathrm{~min}$ ) are related to the main bay where the tide gauge operates. This is consistent with the spectral analysis in Fig. 9(e) which exhibits periods of 8, 10 and 13 min. As it was shown in Section 2, there are differences in the spectral response for the three different tsunamis arriving from different azimuths relative to Marquesas: $110^{\circ}-120^{\circ}$ for the Maule event, $250^{\circ}-260^{\circ}$ for the Samoa and $300^{\circ}$ for the Tohoku event.

\subsection{Azimuthal dependence of the semi-resonant modes}

To study the azimuthal dependence of excitation of the free oscillations, the dynamic method of determination of free oscillations is required. 71 simulations of an initial Gaussian deformation surface were considered around the centre of the Marquesas Archipelago with a rotation increment of $5^{\circ}$. All sources were designed with the same characteristics, that is, a dimension $10^{\circ} \times 5^{\circ}$ and oriented to maximize the impact in the Marquises (azimuth perpendicular to the ray). The source was taken to be big enough so that its dominant period (25-35 $\mathrm{min})$ did not interfere with the eigenperiods of the different bays and islands. As suggested by Rabinovich (1997), the spectral content of a tsunami signal is the combination of the tsunami spectrum near the source region and the different response functions of the ocean, bays and harbours. The study of the dependencies is made for both cases as shown in Fig. 10. In the first one, the sources are close to the archipelago, which can reveal the interaction of the local bathymetry and structure of the Marquesas Archipelago only. The second case, for more distant sources, was designed to demonstrate the influence of the more distant oceanic features (like far-field diffraction, reflection).

Fig. 11 shows the result of the azimuthal dependence for near sources (a for Nuku Hiva and c for Hiva Oa) and for far sources (b and d). These results are computed in the different bays where tide gauges are located and thus are not valid for the entire island. In this polar plot, the spectral amplitude is represented as a function of the geographic azimuth (positive eastwards) and the Fourier periods between 5 and $30 \mathrm{~min}$.

For Nuku Hiva, in the near-source case (Fig. 11a), the results show a good agreement with the determination of the resonant frequency of the Taiohae Bay. All the resonant periods that were determined in the previous section (with a theoretical approach, in Section 3, or by the analysis of real tide gauge data in Section 2) are present with a main oscillation of 15 min which corresponds to the first mode of resonance of the bay. Periods greater than $25 \mathrm{~min}$ are related to the period of the initial sources that are used for this study. Looking at the first mode between 10 and $15 \mathrm{~min}$ of this bay (modes $0-2$ ), we remark that the main oscillation at the 15 -min period is almost 

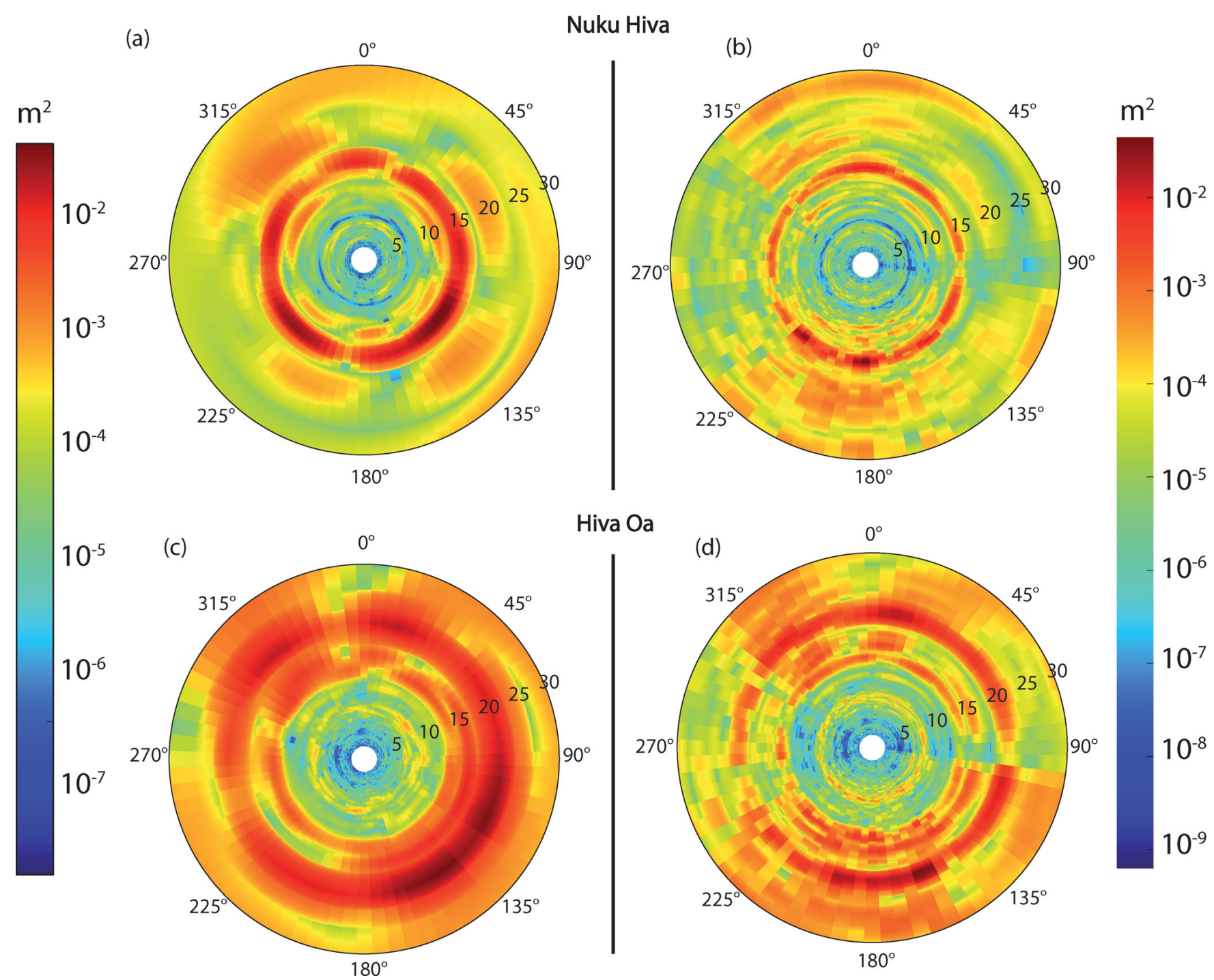

Hiva Oa

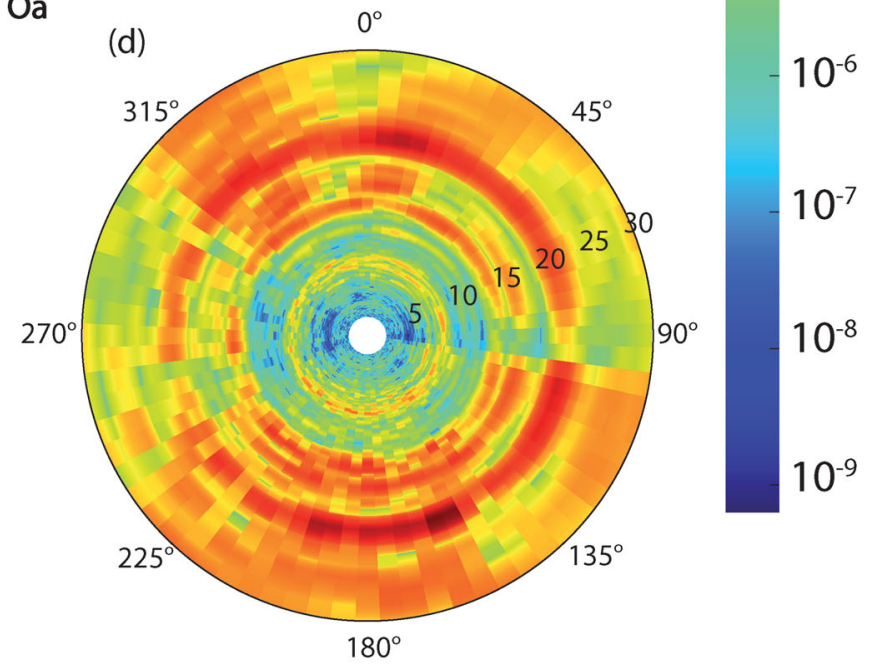

Figure 11. Polar plots of the power spectra depending on the azimuth ( $\theta$ axis) and the periods (radial axis, in minutes) for different islands: (a and $b$ ) for the Nuku Hiva Island, ( $c$ and d) for the Hiva Oa Island and for different source position: (a and c) for near sources, (b and d) for far sources (see Fig. 10 for the source position).

always present, although attenuated for the azimuth of $20^{\circ}, 190^{\circ}$ and $320^{\circ}$. The other periods are not well resolved for azimuths north, east and west. The same analysis was done in the case of the Hiva Oa Island (Fig. 11c), and the main result is that the 22-min oscillation (resonant interaction between Hiva $\mathrm{Oa}$ and Tahuata) is more excited when the waves come from the southeast side.

For distant sources, the spectral maxima of 20-30 min related to the source vanish due to the longer propagation and the dissipation of wave energy. This results in more pronounced variations of the azimuthal dependency showing a complete minimum at all periods when the source is located at an azimuth of $90^{\circ}$ (towards northern Peru) for both bays and a most important signature for the southeast and south sources. A maximum of the spectral coefficients is observed for sources coming from south, but there are no known earthquake sources in that region. Comparing real tide gauge data (Figs 2 and 3) and azimuthal dependencies of the free oscillation, we find a good agreement. For the Samoa event (Figs 2c and 3c), we note that there is not a strong amplification of the free oscillation modes, but only a global amplification due to the increase of the tsunami wave energy. This feature can be found in the azimuthal dependency analysis in direction of $250^{\circ}-260^{\circ}$ of the Samoa source. For the Maule event, the free oscillations of 15 and $8 \mathrm{~min}$ are excited at Nuku Hiva Island, and the 22, 15 and $8 \mathrm{~min}$ at Hiva Oa. As for the Samoa event, these features are observed for the $110^{\circ}-120^{\circ} \mathrm{az}-$ imuths corresponding to the Maule source. Finally, for the Tohoku event observed at Nuku Hiva, we only observe an amplification of the $15 \mathrm{~min}$ oscillation period, more pronounced for the Hiva Oa data, with an amplification of the 22-, 15- and 8-min periods. This is observed when looking at the azimuth of this event $\left(300^{\circ}-310^{\circ}\right)$.

\section{DISCUSSION AND CONCLUSION}

The main objective of this work was to study the free oscillations (eigenperiods) of tsunami waves in French Polynesia and more especially the Marquesas Archipelago, which is the most affected by tsunamis. This was carried out using data for three recent earthquake-generated tsunami events (Samoa 2009, Maule 2010, Tohoku 2011) for which red watch alert were issued by the Pacific Tsunami Warning centre and coastal evacuations. 
The location of French Polynesia, in the middle of the Pacific Ocean, requires studies of tsunami effects as a function of the azimuth of the source. We note that for these three events, the excitation of free oscillation modes depends on the azimuth. The time-series analyses presented in Figs 2 and 3 show that the relative excitation of the resonance periods varies according to the different sources: during high tides the background noise excited the free oscillation modes more than during low tide level. In fact, the mean energy density of the main free oscillation mode during high tide is approximately 10 times higher than during low tide. Free oscillations are amplified by the injection of tsunami wave energy. Once the free oscillations are excited, they attenuate very slowly. In general, the modes persist for several days before returning to the background level.

Testing the influence of removing artificially some bathymetric features on tsunami (seamount), Kowalik et al. (2008) showed that tsunami energy is strongly linked to these bathymetric features. Comparing the evolution of spectrum for different bathymetric configurations, a better comprehension of the influence of the bathymetry could be obtained.

Independently of the fact that this study does not take into account the directivity of the tsunami source and its magnitude, the Tsunami Warning System for French Polynesia in place in Papeete could add the azimuthal dependencies of free oscillation to his warning system, in terms of amplification coefficients or to identify the bays or regions which need more effort to evacuate. The importance to study accurate prediction of late, damaging coastal waves after a large tsunamigenic earthquake was demonstrated by Yamazaki \& Cheung (2011) who showed that the coupling of the shelf resonance and the fundamental oscillation mode in the Bay of Concepcion after the Maule 2010 earthquake resulted in the large unexpected wave that devastated the Talcahuano Harbour. Late tsunami arrivals have also induced damage in Crescent City (Dengler et al. 2008), or during the 2004 tsunami (Okal et al. 2006). In the Marquesas, a field survey showed that some little bays in the north of Hiva Oa had resonant response due to late wave arrivals of the 2010 Maule tsunami, more than $3 \mathrm{hr}$ after the first arrivals (Reymond et al. 2012).

While we have tested here a series of theoretical azimuths, a further step towards prediction would require to use the actual seismological source azimuths around the Pacific rim. Predicting the occurrence and amplitude of these resonances should also definitely help warning systems by assessing the amplification factor and providing the arrival time of late resonant waves.

In this study, we studied tsunami free oscillations in the Marquesas Archipelago. The occurrence of three recent large tsunamis (Samoa 2009, Maule 2010, Tohoku 2011) allow us to use highquality recordings of the complete tsunami waves in the French Polynesia. We identify the different free oscillations modes in these records before and after the tsunami arrivals. The energy added by the tsunami wave amplifies the free oscillations. After the identification of these resonant periods, that are independent of the source location, a site response study is performed to evaluate the azimuthal dependence of the excitation of free oscillations. For islands which are open to the ocean (like French Polynesia, Hawaii) the incidence direction of the tsunami wave (or source location) has a direct influence on the excitation of the free oscillation modes. This is due to the bathymetric configuration of these archipelagos (wave trapping between islands, reflection of wave). This study demonstrates the dependence of the excitation of the mode of tsunami free oscillation on source location, hence on the arrival azimuth of the tsunami.

\section{ACKNOWLEDGEMENTS}

This work is supported by the French ANR programme MAREMOTI under contract ANR-08-RISKNAT-005-01 Computation were performed using HPC resources from GENCI-CCRT (Grant 2011-6702). Our study benefited from discussions with CPPT (D. Reymond) and from improvements by F. Schindelé, A. Loevenbruck and E. Quentel. We thank two anonymous reviewers for their constructive comments.

\section{REFERENCES}

Allen, S.C.R. \& Greenslade, D.J.M., 2009. A spectral climatology of Australian and South-West Pacific tide gauges, Tech. rep., CSIRO.

Allgeyer, S., Daubord, C., Hébert, H., Loevenbruck, A., Schindel, F. \& Madariaga, R., 2012. Could a 1755-like tsunami reach the French Atlantic coastline? constraints from twentieth century observations and numerical modeling, Pure appl. Geophys., 1-17, doi:10.1007/s00024-012-0513-5.

Balay, S. et al., 2008. PETSc Users Manual, Tech. Rep. ANL-95/11 - Revision 3.0.0, Argonne National Laboratory.

Bellotti, G., 2007. Transient response of harbours to long waves under resonance conditions, Coast. Eng., 54(9), 680-693.

Cohen, L., 1989. Time-frequency distributions - a review, Proc. IEEE, 77(7), 941-981.

Crank, J. \& Nicolson, P., 1947. A practical method for numerical evaluation of solutions of partial differential equations of the heat-conduction type, in Mathematical Proceedings of the Cambridge Philosophical Society, Cambridge Univ. Press, Vol. 43, pp. 50-67.

Delouis, B., Nocquet, J.-M. \& Vallee, M., 2010. Slip distribution of the February 27, $2010 m_{w}=8.8$ Maule earthquake, central Chile, from static and high-rate GPS, InSAR, and broadband teleseismic data, Geophys. Res. Lett., 37, L17305.

Dengler, L., Uslu, B., Barberopoulou, A., Borrero, J. \& Synolakis, C., 2008. The vulnerability of Crescent City, California, to tsunamis generated by earthquakes in the Kuril Islands region of the northwestern Pacific, Seismol. Res. Lett., 79, 608-619.

Hébert, H., Heinrich, P., Schindelé, F. \& Piatanesi, A., 2001. Far-field simulation of tsunami propagation in the Pacific Ocean: impact on the Marquesas Islands (French Polynesia), J. geophys. Res., 106(C5), 9161-9177.

Heinrich, P., Schindele, F., Guibourg, S. \& Ihmlé, P., 1998. Modeling of the February 1996 Peruvian tsunami, Geophys. Res. Lett., 25(14), 2687-2690.

Hernandez, V., Roman, J.E. \& Vidal, V., 2005. SLEPc: a scalable and flexible toolkit for the solution of eigenvalue problems, ACM Trans. Math. Softw., 31(3), 351-362.

Horrillo, J., Knight, W. \& Kowalik, Z., 2008. Kuril Islands tsunami of November 2006: 2. Impact at Crescent city by local enhancement, Geophys. Res. Letters, 113(C1), C01021.

Kowalik, Z., Horrillo, J., Knight, W. \& Logan, T., 2008. Kuril Islands tsunami of November 2006: 1. Impact at Crescent city by distant scattering, $J$. geophys. Res., 113(C1), C01020.

Mei, C.C., Stiassnie, M. \& Yue, D.K.-P., 2005. Theory and Applications of Ocean Surface Waves, World Scientific, Singapore; Hackensack, NJ.

Munger, S. \& Cheung, K., 2008. Resonance in Hawaii waters from the 2006 Kuril Islands tsunami, Geophys. Res. Lett., 35(7), L07605.

Okal, E. \& Hébert, H., 2007. Far-field modeling of the 1946 Aleutian tsunami, Geophys. J. Int, 169, 1229-1238.

Okal, E., Borrero, J. \& Synolakis, C., 2004. The earthquake and tsunami of 1865 November 17: evidence for far-field tsunami hazard from Tonga, Geophys. J. Int., 157(1), 164-174.

Okal, E., Sladen, A. \& Okal, A., 2006. Rodrigues, Mauritius, and Réunion islands field survey after the December 2004 Indian Ocean tsunami, Earthq. Spectra, 22, S241-S261.

Rabinovich, A., 1997. Spectral analysis of tsunami waves: separation of source and topography effects, J. geophys. Res.-Oceans, 102(C6), 1266312676. 
Rabinovich, A., 2009. Seiches and harbor oscillations, in Handbook of Coastal and Ocean Engineering, pp. 193-236, World Scientific Pub Co Inc.

Rabinovich, A. \& Thomson, R., 2007. The 26 December 2004 Sumatra tsunami: analysis of tide gauge data from the world ocean part 1. Indian Ocean and South Africa, Pure Appl. geophys., 164, 261-308.

Rabinovich, A., Thomson, R. \& Stephenson, F., 2006. The Sumatra tsunami of 26 December 2004 as observed in the North Pacific and North Atlantic oceans, Surv. Geophys., 27(6), 647-677.

Reymond, D., Hyvernaud, O. \& Talandier, J., 1991. Automatic detection, location and quantification of earthquakes: application to tsunami warning, Pure appl. Geophys., 135(3), 361-382.

Reymond, D., Hyvernaud, O. \& Okal, E.A., 2012. The 2010 and 2011 tsunamis in French Polynesia: operational aspects and field surveys, Pure appl. Geophys, doi:10.1007/s00024-012-0485-5.

Roeber, V., Yamazaki, Y. \& Cheung, K.F., 2010. Resonance and impact of the 2009 Samoa tsunami around Tutuila, American Samoa, Geophys. Res. Lett., 37, L21604.
Sahal, A., Roger, J., Allgeyer, S., Lemaire, B., Hébert, H., Schindele, F. \& Lavigne, F., 2009. The tsunami triggered by the 21 May 2003 Boumerdes-Zemmouri (Algeria) earthquake: field investigations on the French Mediterranean coast and tsunami modelling, Nat. Hazards Earth Syst. Sci., 9(6), 1823-1834.

Sladen, A., Hébert, H., Schindelé, F. \& Reymond, D., 2007. Evaluation of far-field tsunami hazard in French Polynesia based on historical data and numerical simulations, Nat. Hazards Earth Syst. Sci., 7, 195206.

Torrence, C. \& Compo, G., 1998. A practical guide to wavelet analysis, Bull. Am. Meteor. Soc., 79(1), 61-78.

Yalciner, A. \& Pelinovsky, E., 2007. A short cut numerical method for determination of periods of free oscillations for basins with irregular geometry and bathymetry, Ocean Eng., 34(5-6), 747757.

Yamazaki, Y. \& Cheung, K.F., 2011. Shelf resonance and impact of near-field tsunami generated by the 2010 Chile earthquake, Geophys. Res. Lett., 38 , L12605. 